\title{
Smoking Habits and Risk of Benign Breast Disease
}

\author{
FABIO PARAZZINI, * MONICA FERRARONI, * CARLO LA VECCHIA,"† JOHN A BARON, F FABIO \\ LEVI, † SILVIA FRANCESCHIS AND ADRIANO DECARLI* *
}

Parazzini F (Istituto di Ricerche Farmacologiche 'Mario Negri', via Eritrea 62, 20157 Milan, Italy). Ferraroni M, La Vecchia C. Baron J A, Levi F, Franceschi S and Decarli A. Smoking habits and risk of benign breast disease. Internationa/ Journa/ of Epidemiology 1991; 20: 430-434.

The relationship between smoking habits and the risk of benign breast disease (BBD) was analyzed using data from a case-control study conducted between 1981 and 1983 in the greater Milan area, Northern Italy. Cases (n - 288) were women with histologically confirmed BBD (203 dysplesia, 85 benign tumours) referred to the National Cancer Institute of Milan for biopsies. Controls were women $(n=291)$ seen on selected days for a cytological smear for cervical cancer in outpatient clinics of the same Institute. No consistent association emerged between various indicators of smoking habits (smoking status, number of cigarettes smoked per day, duration of smoking) and the risk of BBD. Compared with never smokers the relative risk (RR) of all BBD combined was 0.7 (95\% confidence interval, $\mathrm{Cl}$ : $0.4-1.3$ ) in exsmokers, $1.4(95 \% \mathrm{Cl}: 0.8-2.5)$ in smokers of less than 10 cigarettes per day, and $1.1(95 \% \mathrm{Cl}: 0.7-1.7)$ in smokers of 10 or more cigarettes per day. There was some suggestion that the risk may be below unity post-menopause, but the relative risks for smokers were not statistically different in pre- (RR = $1.2 ; 95 \% \mathrm{Cl}: 0.8-1.8)$ and post-menopausal (RR $-0.6 ; 95 \% \mathrm{Cl}: 0.2-1.7$ ) women. The risk of benign tumours (chiefly fibradenoma) was higher in current smokers, but this finding was not statistically significant (RR $=1.5 ; 95 \% \mathrm{Cl}: 0.9-2.6$ ) and the highest risks were observed in the strata of lighter smokers and those with shorter duration of smoking. Overall these results fail to support a negative association between smoking habits and benign breast disease.

Benign breast disease (BBD) is a heterogeneous group of changes in the female breast that are strongly related to ovarian hormones.' For example, BBD is more frequent in nulliparous women, ${ }^{1-5}$ and tends to disappear after the menopause..$^{5-7}$ Its severity generally increases in the pre-menstrual period. ${ }^{8}$ Further, oral contraceptive use has been associated with a short-term decrease in the risk of BBD, particularly that involving less definite histological changes. ${ }^{9-10}$ Oestrogen replacement therapy has been reported in several, but not all, studies to increase the risk or exacerbate the symptoms of BBD. ${ }^{11-14}$ Similarly, exogenous oestrogen administration has been linked with benign mammary lesions in animal experiments. ${ }^{15-17}$

\footnotetext{
'Istituto di Ricerche Farmacologiche 'Mario Negri', Via Eritrea 62, 20157 Milan, Italy.

*Istituto di Biometria e Statistica Medica, University of Milan, 20133 Milan, Italy.

fInstitute of Social and Preventive Medicine, University of Lausanne, 1005 Lausanne, Switzerland.

¥Department of Community and Family Medicine, Dartmouth Medical School, 03756 Hanover, New Hampshire, USA.

\$ncological Referral Centre, 33081 Aviano, Pordenone, Italy.
}

Cigarette smoking has been shown to reduce oestradiol levels and availability in women taking oral oestradiol, ${ }^{18}$ and women who smoke have lower urinary oestrogen levels during the luteal phase of the menstrual cycle compared to non-smokers. ${ }^{19}$ More generally, it is thought that women who smoke cigarettes behave as though they are relatively oestrogendeficient. Thus, smoking women show an increased risk of osteoporosis and early menopause, and a decreased frequency of endometrial cancer, ${ }^{20,21}$ and probably of uterine fibroids ${ }^{22}$ and pelvic endometriosis. ${ }^{23}$

Although these observations suggest that the risk of BBD might be lower in smokers, the epidemiological evidence is inconsistent. ${ }^{3,14,21,2428}$ For example, Berkowitz et al. ${ }^{25}$ analysing data from a hospital-based casecontrol study conducted in the US found that current smokers, particularly post-menopausal women were at decreased risk of fibrocystic and benign breast tumours. The relative risk (RR) for current smokers was 0.7 for fibrocystic breast disease, 0.6 for fibroadenoma, and RRs of similar magnitude were registered for other or combined histological types. A similar association for fibrocystic disease was reported by 
Wyshak et al. in a cross-sectional surveillance of more than 5000 former college alumnae, ${ }^{27}$ but the association was not significant for former smokers. No association emerged in at least three case-control and cohort studies conducted in the UK, ${ }^{26}$ Australia ${ }^{28}$ and the $\mathrm{US}^{3}$ in which the diagnosis of BBD was selfreported $^{26}$ or histologically confirmed. ${ }^{3.28}$

The contrasting results have been attributed to differing study design (cohort versus case-control, population-based versus hospital-based), although it is difficult to explain all the apparent contradictions on this basis alone. Other possible reasons for the apparent discrepancies could be due to the age distribution of cases studied, since any effect of smoking could be more evident in post-menopausal women. ${ }^{14,21,25}$

In this paper we report the results of a case-control study conducted in Italy in the early 1980 s on the relation between smoking habits and histologicallyconfirmed BBD. Specific attention was paid to collecting detailed information on the histopathological classification of cases.

\section{SUBJECTS AND METHODS}

Between November 1981 and March 1983 we conducted a hospital-based case-control study of BBD. The design of the investigation has already been described. ${ }^{5}$ Briefly, trained interviewers identified and questioned cases and controls using a structured questionnaire including information on sociodemographic factors and personal characteristics and habits, gynaecological and obstetric data, related medical history and use of selected medication. Questions on smoking included smoking status (ever-smokers being defined as subjects who had smoked at least one cigarette per day for at least one year; exsmokers those who had stopped at least one year previously). The smokers and exsmokers were asked the total duration (in years) of the habit and the average number of cigarettes smoked per day.

Cases were women with histologically confirmed BBD admitted for the first time to the Division of Medical Oncology of the Milan Cancer Institute to undergo breast biopsy. A total of 288 women aged 17-64 years (median age 41) met these criteria. Among them, $85(30 \%)$ had benign tumours (77 fibroadenomas and 8 papillomas) and $203(70 \%)$ had dysplastic lesions (21 ductal hyperplasias, 49 other dysplasias such as fibrosclerosis or adenosis, and 133 mixed lesions). Only clinically important breast lumps, often suspected of malignancy, are referred for biopsy at the National Cancer Institute in Milan. It represents a 'second level' refersal centre from a network of outpatient clinics covering the Great Milan area, for surveillance and diagnosis of breast diseases.
Eligible controls were women seen on selected days for a cytological smear for cervical cancer in outpatient clinics of the National Cancer Institute of Milan. These women should constitute a representative sample of the population in the area attending routine cervical screening centres. A total of 291 women aged 18 to 68 (median age 40) were identified. None of the eligible cases or controls refused to be interviewed. Although cases and controls were not strictly matched, their age distribution was comparable (Table 1).

\section{Data Analysis}

We estimated the odds ratios of $\mathrm{BBD}$, as estimators of (RRs), together with their $95 \%$ confidence intervals (CI), according to smoking habits, from data stratified for quinquennia of age by the Mantel-Haenszel procedure. ${ }^{29}$ In order to allow for the effects of several potential confounding factors simultaneously, unconditional multiple logistic regression, with maximum likelihood fitting, ${ }^{30}$ was used. Included in the regression equations were terms for age, education, menopausal status, Quetelet's index, parity, age at menarche, oral contraceptive use and, in turn, various indicators of smoking habits.

\section{RESULTS}

The distribution of cases and controls according to histopathological classification, age and selected characteristics is shown in Table 1. As expected, women with benign tumours were younger than those with dysplasias $(42 \%$ and $22 \%$ respectively were less than 35 years old). No significant difference emerged in relation to menopausal status or Quetelet's index.

The smoking habits of cases and controls and the smoking-associated risks are considered in Table 2 and Table 3. No consistent association emerged between

TABLE 1 Distribution of 288 cases of benign breast disease and 291 controls according to selected characteristics Milan, Italy, I981-83

\begin{tabular}{|c|c|c|c|c|c|c|}
\hline & \multicolumn{4}{|c|}{ Cases } & & \\
\hline & \multicolumn{2}{|c|}{ Benign tumours } & \multicolumn{2}{|c|}{ Dysplasias } & \multicolumn{2}{|c|}{ Controls } \\
\hline & No. & $\%$ & No. & $\%$ & No. & $\%_{0}$ \\
\hline \multicolumn{7}{|c|}{ Age (years) } \\
\hline$\leq 25$ & 13 & 15 & 8 & 4 & 21 & 7 \\
\hline $26-35$ & 23 & 27 & 37 & 18 & 62 & 21 \\
\hline $36-45$ & 33 & 39 & 88 & 43 & 130 & 45 \\
\hline $46-55$ & 15 & 18 & 51 & 25 & 59 & 20 \\
\hline$\geq 56$ & 1 & 1 & 19 & 9 & 19 & 7 \\
\hline \multicolumn{7}{|c|}{ Menopausal status } \\
\hline Pre: & 78 & 92 & 163 & 80 & 249 & 86 \\
\hline Post & 7 & 8 & 40 & 20 & 42 & 14 \\
\hline \multicolumn{7}{|c|}{ Quetelet's index $\left(\mathrm{kg} / \mathrm{m}^{2}\right)$} \\
\hline$\leqslant 20$ & 32 & 38 & 64 & 32 & 88 & 30 \\
\hline $20-22$ & 25 & 29 & 57 & 28 & 80 & 27 \\
\hline$\geq 23$ & 28 & 33 & 82 & 40 & 123 & 42 \\
\hline
\end{tabular}


various indicators of smoking habits (smoking status, number of cigarettes smoked per day, or duration of smoking) and risk of BBD. Compared with never smokers, the overall RR for all BBD was $0.7(95 \% \mathrm{CI}$ : 0.4-1.3) for exsmokers, and 1.1 (95\% CI: 0.8-1.6) for current smokers. Among current smokers the RR was 1.4 for fewer than 10 and 1.0 for 10 or more cigarettes smoked per day. Likewise, there was no relationship with duration of smoking, with RRs of 1.1 for $<20$ and 1.2 for $\geqslant 20$ cigarettes per day. The risk of benign tumours (chiefly fibroadenoma') was higher in current smokers, but this finding was not statistically significant $(R R=1.5 ; 95 \% C I: 0.9-2.5)$, and the highest risks were observed in strata of lighter smokers and shorter duration of smoking. All the multivariate RRs were largely comparable to the age-adjusted ones.

The effect of smoking was also calculated by menopausal status. Post-menopausal women were defined as women whose last menstrual cycles occurred at least one year before interview. Among pre-menopausal and post-menopausal women the RR of benign breast disease for current smokers was respectively $1.2(95 \%$ CI: $0.8-1.8)$ and $0.6(95 \% \mathrm{CI}: 0.2-1.7)$, and $0.7(95 \%$ CI: $0.3-1.3)$ and 0.8 (95\% CI: $0.2-3.1)$ for exsmokers. The post-menopausal risks were, however, based on seven current and five exsmoker cases versus 14 current and three exsmoker controls only.

\section{DISCUSSION}

The results of this analysis do not show any consistent association between smoking habits and risk of histologically confirmed breast dysplasia or benign tumours. The overall absence of an association was confirmed in separate strata of histopathological diagnosis of BBD.

It should be stressed that the subjects included in the present study are not representative of all cases of clinical BBD. They were chosen because they had path-

TABle 2 Distribution of 288 cases of benign breast disease and 291 controls according to smoking habits. Milan, Italy, 1981-83

\begin{tabular}{|c|c|c|c|c|c|c|}
\hline & \multicolumn{4}{|c|}{ Cases } & & \\
\hline & \multicolumn{2}{|c|}{ Benıgn tumours } & \multicolumn{2}{|c|}{ Dysplasias } & \multicolumn{2}{|c|}{ Controls } \\
\hline & No. & $\%$ & No. & $x_{0}$ & No. & $\%$ \\
\hline \multicolumn{7}{|c|}{ Smoking habits } \\
\hline Never & 47 & 55 & 132 & 65 & 182 & 63 \\
\hline Ex & 5 & 6 & 14 & 7 & 28 & 10 \\
\hline \multicolumn{7}{|c|}{ Current (cigarettes/day) } \\
\hline$<10$ & 18 & 21 & 21 & 10 & 29 & 10 \\
\hline$>10$ & 15 & 18 & 36 & 18 & 52 & 19 \\
\hline \multicolumn{7}{|c|}{ Duration of smoking (years) } \\
\hline$<20$ & 34 & 89 & $46^{*}$ & 68 & $83^{*}$ & 78 \\
\hline$\geq 20$ & 4 & 11 & 22 & 32 & 23 & 22 \\
\hline
\end{tabular}

"The sum does not add to the total due to some missing values. ologically confirmed benign breast lesions often suspected of being malignant and were referred for biopsy to the Cancer Institute in Milan. Selection is probably the major source of potential bias in studies of $\mathrm{BBD}$ and of benign conditions in general. ${ }^{5}$ For example, benign breast lumps may be more frequently detected in women more conscious of health issues (including for example the health consequences of smoking). In this regard women referred for cervical screening seemed an appropriate choice as controls because of their likely comparable attitudes to health. Further, this control group, although identified and interviewed in hospital, does not share the limitation of hospital controls, particularly the potential over-representation of smokers. ${ }^{20}$ Further, these women were not specifically referred for cervical abnormalities or genital infections, and should therefore be a representative sample of women attending a routine screening procedure. Among the determinants of cervical screening in this population are higher education and social class (which, if anything, tend to be higher in BBD cases too), but not smoking. ${ }^{31}$

It is unlikely that case-control status influenced the reporting of smoking habits, since at the time of data collection the potential association between smoking and $\mathrm{BBD}$ had not received widespread attention in Italy. With regard to confounding, allowing for major potential distorting factors (including socioeconomic status or potential risk factors for BBD) did not appreciably change the estimated RR.

Clinical and experimental observations have suggested that oestrogens may play a role in the development of BBD. However, available epidemiological evidence regarding a possible association with smoking appears inconsistent (see Table 4 for a review). Among seven studies considered ${ }^{3.14,24-28}$ an inverse association was found between smoking habits and fibrocystic disease in two case-control ${ }^{14.25}$ and one cross-sectional study. ${ }^{27}$ Fibroadenoma was inversely associated with smoking status in a case-control study ${ }^{23}$ and a weak inverse association was observed in the Walnut Creek cohort investigation. ${ }^{24}$ Other studies, however found risks of $\mathrm{BBD}$ in smokers around unity. ${ }^{26.28} \mathrm{~A}$ direct relationship between smoking and cystic disease (but not fibroadenoma) was reported in a population-based case-control study from Washington county, ${ }^{3}$ perhaps reflecting incomplete adjustment for socioeconomic correlates.

These apparent discrepancies are only partly explained in terms of potential bias, different study designs or diagnostic criteria. For example no association with smoking was observed in studies considering either clinical ${ }^{26}$ or histologically confirmed ${ }^{28}$ diagnosis 
TABLE 3 Relative risk (and 95\% confidence interval) of benign breast disease according to histopathological classification and selected indicators of smoking habits. Milan, Laly, $1981-83$

\begin{tabular}{|c|c|c|c|c|c|c|}
\hline & \multicolumn{2}{|c|}{ Benign tumours } & \multicolumn{2}{|c|}{ Dysplasias } & \multicolumn{2}{|c|}{ Total } \\
\hline & MH† & MLV‡ & $\mathbf{M H} \dagger$ & MLV $\ddagger$ & MH† & MLV $\ddagger$ \\
\hline \multicolumn{7}{|l|}{ Smokıng habits } \\
\hline Never & $1^{*}$ & $1^{*}$ & $1^{*}$ & $1 *$ & $1^{*}$ & $1^{*}$ \\
\hline Ex & $\begin{array}{c}0.7 \\
(0.3-1.9)\end{array}$ & $\begin{array}{c}0.6 \\
(02-1.8)\end{array}$ & $\begin{array}{c}0.7 \\
(0.4-1.4)\end{array}$ & $\begin{array}{c}0.7 \\
(0.3-1.4)\end{array}$ & $\begin{array}{c}0.7 \\
(04-1.3)\end{array}$ & $\begin{array}{c}0.7 \\
(0.4-1.3)\end{array}$ \\
\hline Current (all) & $\begin{array}{c}1.5 \\
(0.9-2.5)\end{array}$ & $\begin{array}{c}1.5 \\
(0-2.6)\end{array}$ & $\begin{array}{c}1.0 \\
(0.7-1.5)\end{array}$ & $\begin{array}{c}1.1 \\
(0.7-1.6)\end{array}$ & $\begin{array}{c}1.1 \\
(0.8-1.6)\end{array}$ & $\begin{array}{c}1.2 \\
(0.8-1.8)\end{array}$ \\
\hline \multicolumn{7}{|c|}{ Current (no. of cigarettes/day) } \\
\hline$<10$ & $\begin{array}{c}2.3 \\
(1.1-4.4)\end{array}$ & $\begin{array}{c}2.3 \\
(1.1-4.8)\end{array}$ & $\begin{array}{c}1.0 \\
(0.6-1.6)\end{array}$ & $\begin{array}{c}11 \\
(0.6-2.1)\end{array}$ & $\begin{array}{c}1.4 \\
(0.8-2.3)\end{array}$ & $\begin{array}{c}1.4 \\
(0.8-2.5)\end{array}$ \\
\hline$\$ 10$ & $\begin{array}{c}1.0 \\
(0.5-2.0)\end{array}$ & $\begin{array}{c}1.0 \\
(0.5-2.1)\end{array}$ & $\begin{array}{c}1.0 \\
(0.6-1.6)\end{array}$ & $\begin{array}{c}10 \\
(06-1.7)\end{array}$ & $\begin{array}{c}1.0 \\
(0.6-1.6)\end{array}$ & $\begin{array}{c}1.1 \\
(0.7-1.7)\end{array}$ \\
\hline \multicolumn{7}{|c|}{ Duration of smoking (years) } \\
\hline$<20$ & $\begin{array}{c}1.6 \\
(0.9-2.8)\end{array}$ & $\begin{array}{c}1.6 \\
(0.9-3.0)\end{array}$ & $\begin{array}{c}0.9 \\
(0.5-1.4)\end{array}$ & $\begin{array}{c}0.9 \\
(0.6-1.6)\end{array}$ & $\begin{array}{c}1.1 \\
(0.7-1.6)\end{array}$ & $\begin{array}{c}1.2 \\
(0.8-1.8)\end{array}$ \\
\hline$\geq 20$ & $\begin{array}{c}0.9 \\
(0.3-3.0)\end{array}$ & $\begin{array}{c}1.1 \\
(0.3-3.5)\end{array}$ & $\begin{array}{c}1.3 \\
(0.7-2.6)\end{array}$ & $\begin{array}{c}14 \\
(0.7-2.8)\end{array}$ & $\begin{array}{c}1.2 \\
(0.6-2.4)\end{array}$ & $\begin{array}{c}1.3 \\
(0.7-2.6)\end{array}$ \\
\hline
\end{tabular}

†Mantel Haenszel estimates adjusted for age only.

$\ddagger$ Estimates from multiple logistıc regression equations including terms for age, education, menopausal status, Quetelet's index, parity, age at menarche, oral contraceptive use and, in tum, the above variables.

* Reference category.

of breast disease. In most studies, however, the case series consisted of women seen for biopsy or surgery of a breast lump and a potential protective effect could be stronger on less definite (functional) lesions, as sug- gested for oral contraceptives. ${ }^{10}$ Similarly scanty data are available on post-menopausal women, where the anti-oestrogenic effect of smoking could be more relevant. ${ }^{21}$ Two American case-control studies showing a

TABLE 4 Main results from selected epidemiological studies an the relationship between smoking habits and risk of benign breast disease

\begin{tabular}{ll}
\hline $\begin{array}{l}\text { Authors, country, } \\
\text { year }\end{array}$ & $\begin{array}{l}\text { Study design (number of } \\
\text { considered patients) }\end{array}$ \\
\hline $\begin{array}{l}\text { Nomura et al, US } \\
1977^{3}\end{array}$ & Case $(n=320)$-control $(\mathrm{n}=320)$ study. \\
Walnut Creek & Histologically confirmed diagnosis. \\
study, US $1981^{24}$ & Cohort study. \\
Berkowitz el al., & Hospital discharge diagnoses \\
US $1985^{35}$ & Case $(n=959)$-control $(n=1062)$ study.
\end{tabular}

Mant et al., UK $1986^{2}$

Pastides, US $1987^{14}$

Wyshak et al, US

$1988^{27}$

Rohan et al.

Australia $1989^{3}$
Cohort study (Oxford-Family Planning Association Contraceptive study). Mainly pre-menopausal women.

Case $(n=255)$ - control $(n=787)$ study. Post-menopausal women only. Histologically confirmed diagnosis. Cross-sectional analysis of 5398 college alumnae (aged $21-80$ years).

Diagnosis self-reported.

Case ( $n=383$ )-control study; two control groups: community controls $(n=383)$ and biopsy controds $(n=192)$.

Histologically confirmed diagnoses.
Main results

$R^{*}$ ever versus never smokers $=1.8$ for cystic disease and 0.8 for fibroadenoma.

Heavy smokers appeared to be at slightly decreased risk of fibroadenoma.

RR (adjusted for age and Queletet's index) current smokers versus never $=0.6(95 \% \mathrm{Cl}$ : $0.5-0.8)$ for fibrocystic disease, $0.7(95 \% \mathrm{Cl}$ : $0.5-0.9)$ for fibroadenoma and $0.6(95 \% \mathrm{CI}: 0.3-$ $1.0)$ for mixed lesion. No association in exsmokers. Stronger association in postmenopause.

The first hospital visit rates for BBD were 5.7, 5.9 and $6.4 / 1000$ woman-years respectively in never smokers and in current smokers of 1,14 and 15 or more cigarettes/day.

RR (age-adjusted) ever versus never smokers $=0.5(95 \% \mathrm{Cl}: 0.2-0.8)$ for fibrocystic disease.

RR of current versus never smokers $=0.5$ (95\% $\mathrm{Cl}: 0.3-0.8$ ) for breast biopsy or fibrocystic disease.

RR current smokers versus never $=0.9$ (95\% CI: $0.7-1.3$ ) versus community controls and 1.1 (95\% Cl: $0.7-1.6$ ) versus biopsy controls. No association both in pre- and post-menopause.

- $\mathrm{RR}=$ relative risk; $\mathrm{Cl}=$ confidence interval. 
protective effect of smoking on BBD found a stronger relationship in post-menopausal women, ${ }^{14,25}$ but an Australian study of proliferative lesions did not observe any relationship in either pre- or post-menopausal women. ${ }^{28}$ In our series the risk of $\mathrm{BBD}$ was about $40 \%$ lower in post-menopausal current smokers; this finding was based on seven current smokers cases only and was not statistically significant. The present study, therefore, provides only limited information on the relationship between smoking and BBD after menopause.

In conclusion, despite a plausible biological rationale,$^{21}$ and some suggestive previous findings, the present data (as well as several other studies) fail to support the presence of a consistent negative association between smoking and BBD.

\section{ACKNOWLEDGEMENTS}

This study was conducted within the framework of the CNR (Italian National Research Council) Applied Projects 'Oncology' (Contract No. 88.00719.44) and 'Prevention and Control of Disease Factors'. The contribution of the Italian League Against Tumours and of the Italian Association for Cancer Research, Milan, Italy, are gratefully acknowledged.

\section{IEThster VL. The epidemology of beng}

' Emster V L. The epidemılogy of benıgn breast disease. Epidemiol Rev 1981; 3: 184-202.

${ }^{2}$ Kelsey J L, Lindfors K K, white C A case-control study of the epidemiology of benign breast disease with reference to oral contraceptive use Int J Epidemiol 1974; 3: 333-40.

${ }^{3}$ Nomura A, Comstock G W, Tonascia J. Epidemiologic characteristics of benign breast disease. Am J Epidemiol 1977; 105: 505-12.

4 Hislop T G, Elwood J M. Risk factors for benign breast disease: a 30-year cohort study. Can Med Assoc J 1981; 124: 283-91.

'Parazzini F, La Vecchı C, Franceschi S, Decarli A, Gallus G, Regallo M, Liberati A, Tognonı G. Risk factors for pathologically confirmed benign breast disease. Am J Epidemial 1984; 120: 115-22.

- Cole P, Elwood M, Kaplan S D. Incidence rates and risk factors of benign breast neoplasms. Am J Epidemiol 1978; 108: 112-20.

' Duffy S W, Roberts M M, Elton R A. Risk factors relevant to cystic breast disease: a case-control study. I Epidemuol Comm Hlth 1983; 37: 271-3.

" Preece PE, Hughes LE, Mansel RE, Baum M, Bolton PM, Gravelle I H. Clinical syndromes of mastalgia. Lancet 1986; if: 670-3

' LiVolsi V A, Stadel B V, Kelsey J L, Holford T R, White C. Fibrocystıc breast disease in oral-contraceptive users. A histopathological evaluation of epithelial atypia. $N$ Engl J Med 1078; 299: 381-5.

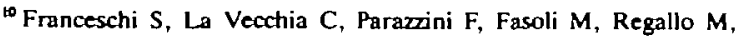
Decarli A, Gallus G, Tognoni G. Oral contraceptives and benign breast disease: a case-control study. Am J Obsiet Gynecol 1984; 149: 602-6.

"Trapido E J, Brinton L A, Schairer C, Hoover R. Estrogen replacement therapy and benign breast disease. I Natl Cancer Inst 1984; 73: 1101-5.
${ }^{1}$ Berkowiz G S, Kelsey J L, Holford T L, et al. Estrogen replacement therapy and fibrocystic disease in post-menopausal women. Am J Epidemiol 1985; 121: 238-45

13 Jick S S, Walker A M, Jick H. Conjugated estrogens and fibrocystic breast disease. Am J Epidemeol 1985; 124:1 746-51.

${ }^{14}$ Pastides H, Najjar M A, Kelsey J L. Estrogen replacement therapy and fibrocystic breast disease. Am J Prev Med 1987; 3: 282-6.

${ }^{15}$ Heiman J Comparative effects of estrogen, testosterone and progesterone on benign tumours of the rat. Cancer Res 1943; 3: $65-9$.

${ }^{16}$ Bassler R. The morphology of hormone induced structural changes in the female breast Curr Topics Pathol 1979; 53: 1-89

17 Yoshida H, Fukunishi R. Effects of sex steroids on the development of 7, 12-Dimethylbenz(a) anthracene-induced mammary dysplasia in neonatally androgenized female rats. Gann 1981, 72: 315-7

uensen J, Christuansen C Effects of smoking on serum I ipoproteins and bone mineral content during post-menopausal hormone replacement therapy. Am J Obstet Gynecol 1988; 159: 820-5.

19 MacMahon B, Trichopoulos D, Cole P, Brown J. Cigarette smokıng and urinary estrogens. $N$ Engl $J$ Med 1982; 307: 1062-5

${ }^{20}$ Baron J A. Smoking and estrogen-related diseases. Am J Epidemiol 1984; 119: 9-22

${ }^{21}$ Baron J A, La Vecchia C, Levi F. The 'anti-estrogenuc' effect of crgarette smoking in women. Am J Obstet Gynecol 1990; 162: 502-14.

${ }^{2}$ Parazzin F, La Vecchı C, Negn E, Cecchetti G, Fedele L. Epıdemiologic characteristics of women with utenne fibroids: a casecontrol study Obstet Gynecol 1988; 72: 853-7.

${ }^{2}$ Parazzıni F, La Vecchı C, Franceschı S, Negri E, Cecchettı G. Risk factor for endometroid, mucinous and serous benign ovarian cysts. Int J Epidemiol 1989; 18: 108-12.

${ }^{24}$ Ramcharan S, Pellegrin FA, Ray R, Hsu J P. The Walnut Creek Conirceptive Drug Study. A prospective study of the side effects of oral contracepuves. Vol. III, NIH Publ No 81-564, 1981

${ }^{2}$ Berkowiz G S, Canny PF, LiVolsi V A, Merino M J, O'Connor $\mathrm{T} Z$, Kelsey J L. Cigarette smoking and benign breast cancer. J Eptdemiol Comm Hlth 1985; 39: 308-13.

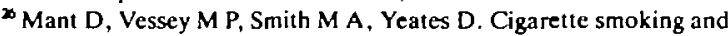
benign breast disease (letter). J Epidemiol Comm Hlth 1986; 40: $277-8$.

${ }^{27}$ Wyshak G, Fnsch R E, Albright N L, Albright T E, Schiff I. (letter). Cigarette smoking and benign breast disease $N$ Engl $J$ Med 1988; 319: 736-7.

2 Rohan TE, Cook M G, Baron J A. Cigarette smoking and benign proliferative epthelial disorders of the breast in women: a case-control study J Epidemiol Comm Hlih 1989; 43: 362-8.

- Mantel N, Haenszel W. Statistical aspects of the analysis of data from reprospective studies of disease. I Natl Cancer Inst 1959; 22: $719-48$

* Baker RJ, Nelder J A. The GLIM System: Release 3. Oxford: Numerical Algonthms Group, 1978.

${ }^{31}$ Parazzini F, Negn E, La Vecchia C. Characteristics of women reporting cervical screening. Tumori, 1990; 76: 585-9.

(Revised version received November 1990) 